\title{
Sieboldine A, A Novel Tetracyclic Alkaloid from Lycopodium sieboldii, Inhibiting Acetylcholinesterase
}

Yusuke Hirasawa, ${ }^{\dagger}$ Hiroshi Morita ${ }^{\dagger}$ Motoo Shiro, ${ }^{\dagger}$ and Jun’ichi Kobayashi*, ${ }^{\dagger}$

${ }^{\dagger}$ Graduate School of Pharmaceutical Sciences, Hokkaido University, Sapporo 060-0812, Japan and ${ }^{\ddagger}$ X-Ray Research Laboratory, Rigaku Corporation, Akishima, Tokyo 196-8666, Japan

\section{Supporting Information}

Figure $\mathrm{S} 1 . \quad{ }^{1} \mathrm{H}$ NMR spectrum of sieboldine $\mathrm{A}(\mathbf{1})$ in $\mathrm{CD}_{3} \mathrm{OD}$.

Figure S2. $\quad{ }^{13} \mathrm{C}$ NMR spectrum of sieboldine $\mathrm{A}(\mathbf{1})$ in $\mathrm{CD}_{3} \mathrm{OD}$.

Figure S3. $\quad{ }^{1} \mathrm{H}-{ }^{1} \mathrm{H}$ COSY spectrum of sieboldine A (1) in $\mathrm{CD}_{3} \mathrm{OD}$.

Figure S4. HOHAHA spectrum of sieboldine $\mathrm{A}(\mathbf{1})$ in $\mathrm{CD}_{3} \mathrm{OD}$.

Figure S5. NOESY spectrum of sieboldine $\mathrm{A}(\mathbf{1})$ in $\mathrm{CD}_{3} \mathrm{OD}$.

Figure S6. HMQC spectrum of sieboldine $\mathrm{A}(\mathbf{1})$ in $\mathrm{CD}_{3} \mathrm{OD}$.

Figure S7. $\mathrm{HMBC}$ spectrum of sieboldine $\mathrm{A}(\mathbf{1})$ in $\mathrm{CD}_{3} \mathrm{OD}$. 


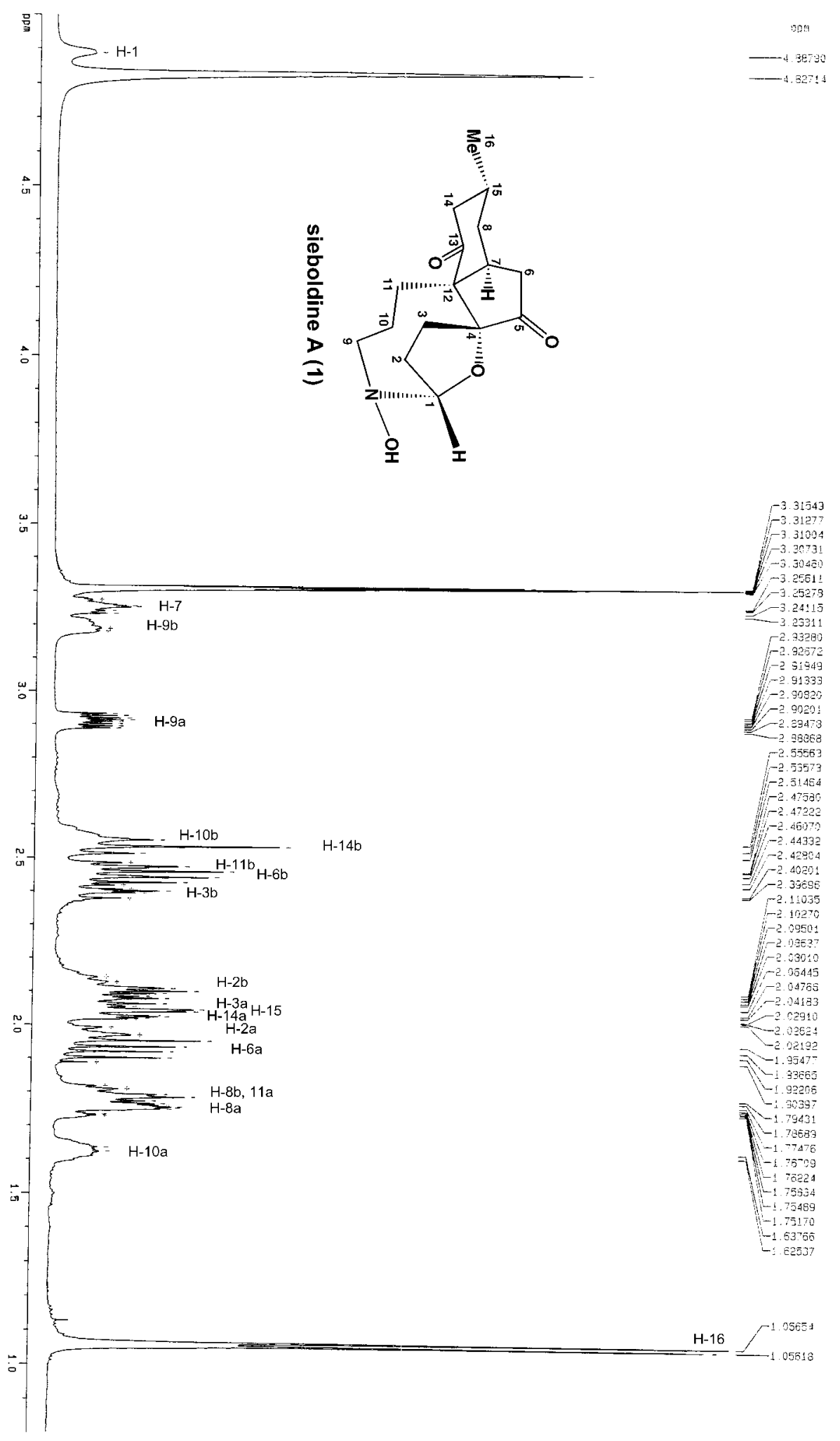

Figure S1. $\quad{ }^{1} \mathrm{H}$ NMR spectrum of sieboldine $\mathrm{A}(\mathbf{1})$ in $\mathrm{CD}_{3} \mathrm{OD}$. 


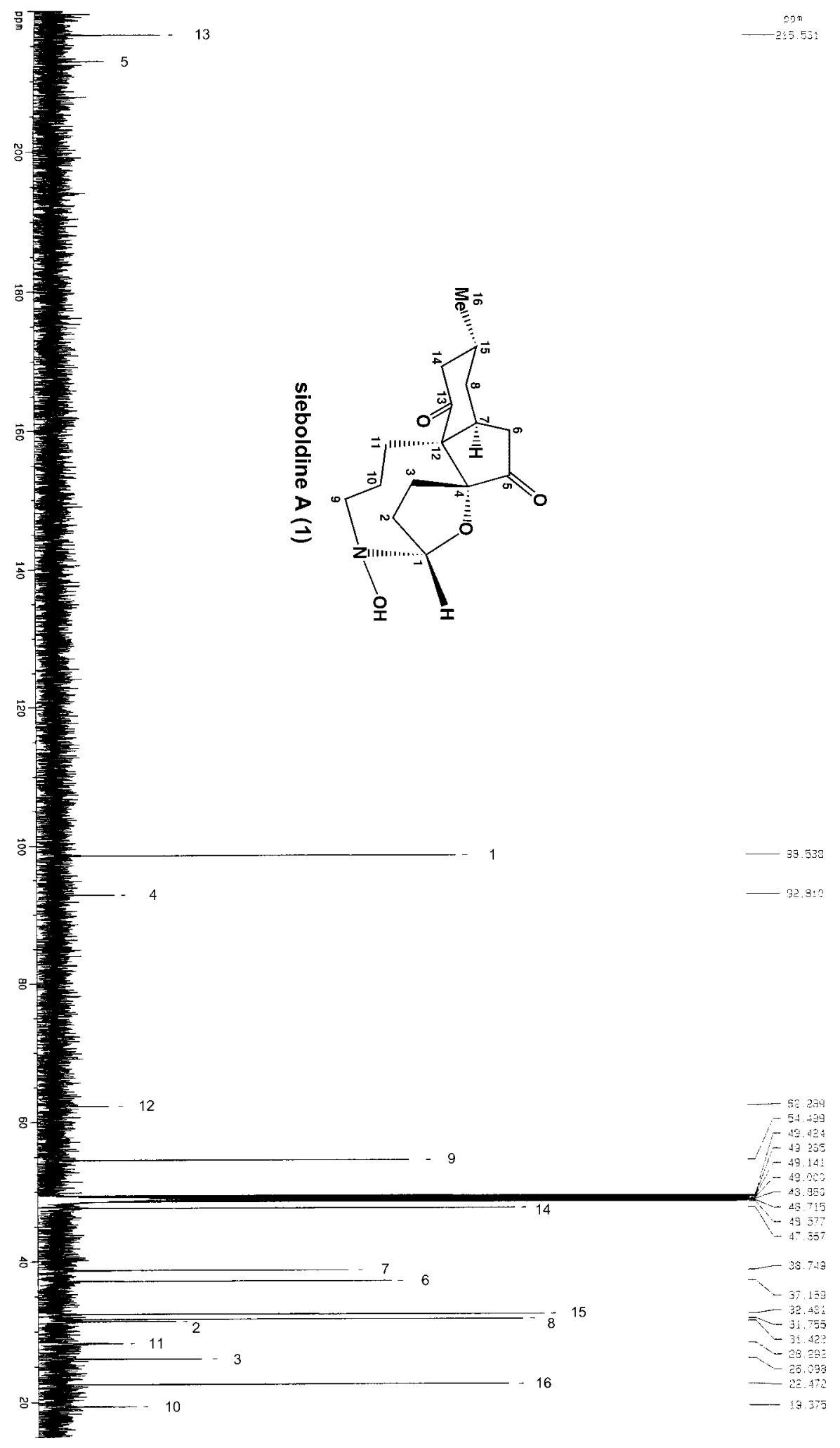

Figure S2. $\quad{ }^{13} \mathrm{C}$ NMR spectrum of sieboldine $\mathrm{A}(\mathbf{1})$ in $\mathrm{CD}_{3} \mathrm{OD}$. 


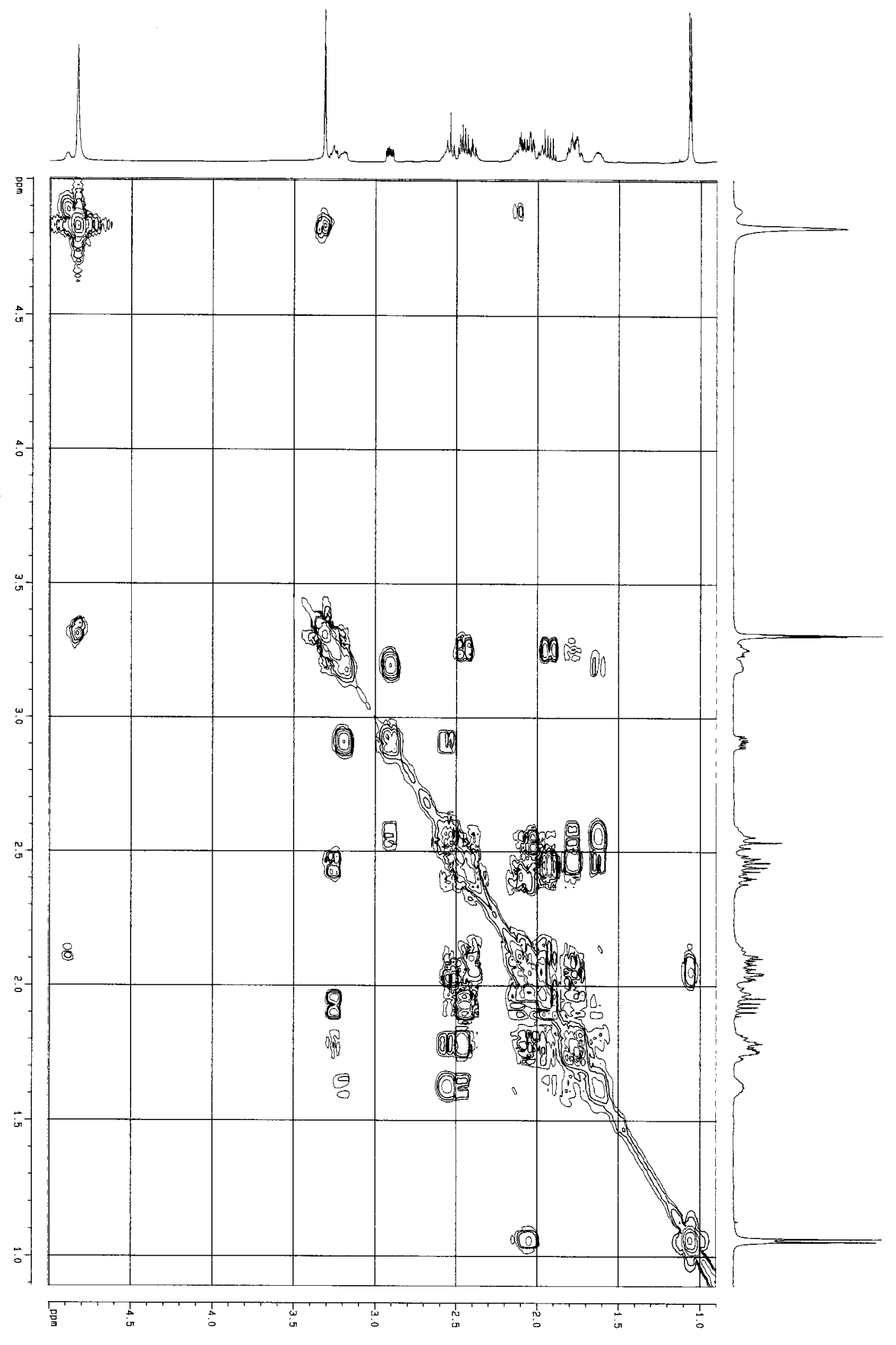

Figure S3. $\quad{ }^{1} \mathrm{H}-{ }^{1} \mathrm{H}$ COSY spectrum of sieboldine $\mathrm{A}(\mathbf{1})$ in $\mathrm{CD}_{3} \mathrm{OD}$. 


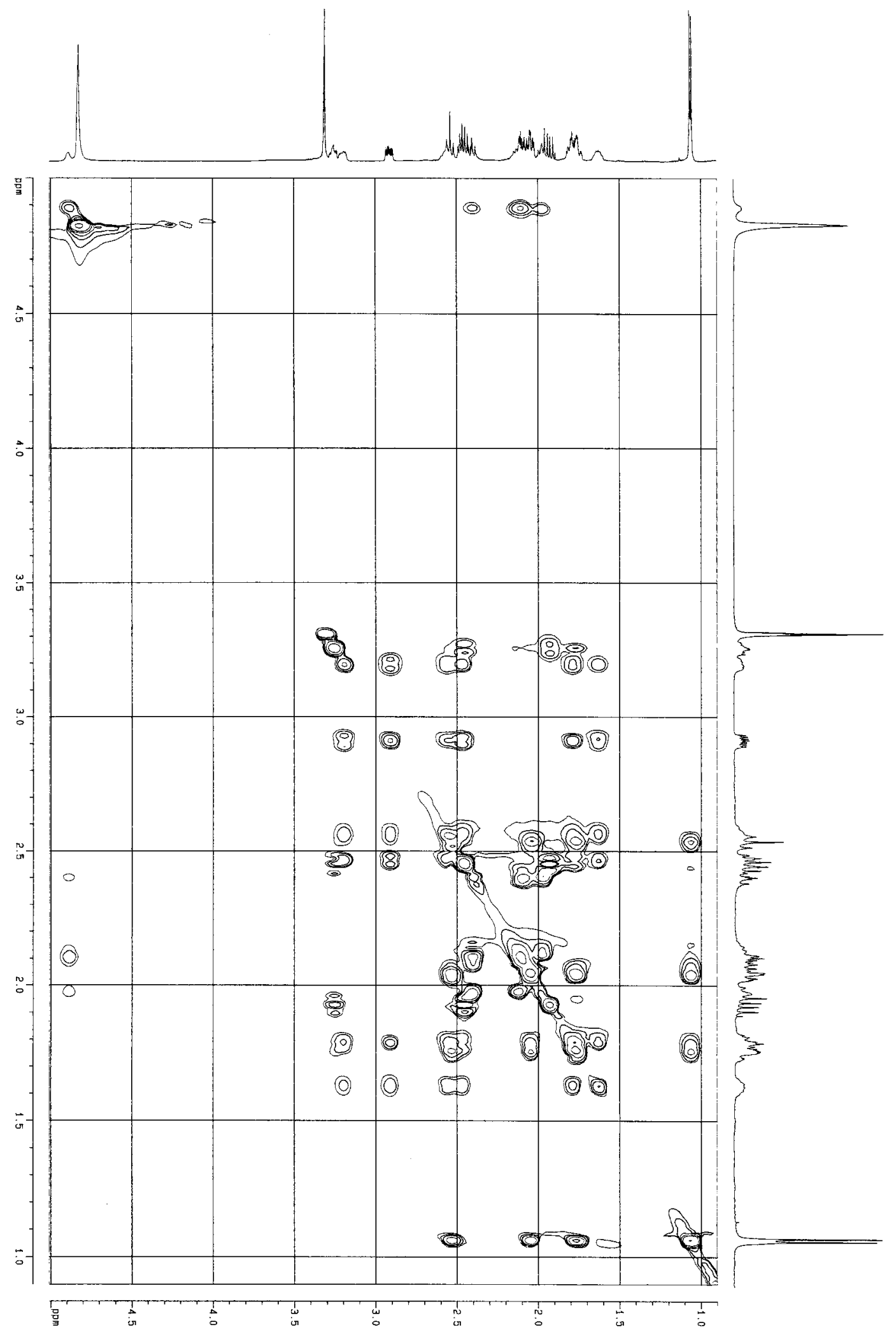

Figure S4. HOHAHA spectrum of sieboldine $\mathrm{A}(\mathbf{1})$ in $\mathrm{CD}_{3} \mathrm{OD}$. 


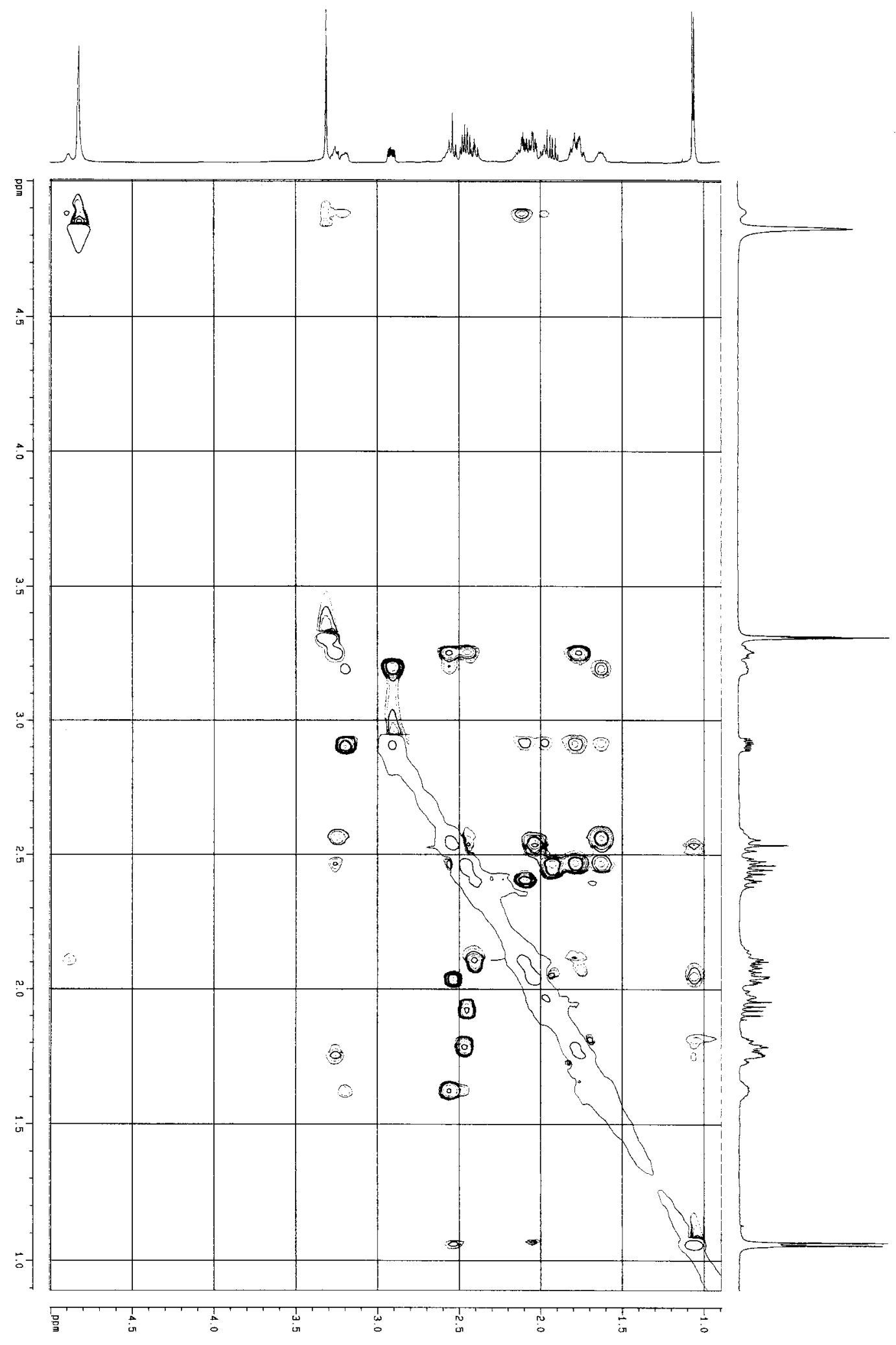

Figure S5. NOESY spectrum of sieboldine $\mathrm{A}(\mathbf{1})$ in $\mathrm{CD}_{3} \mathrm{OD}$. 


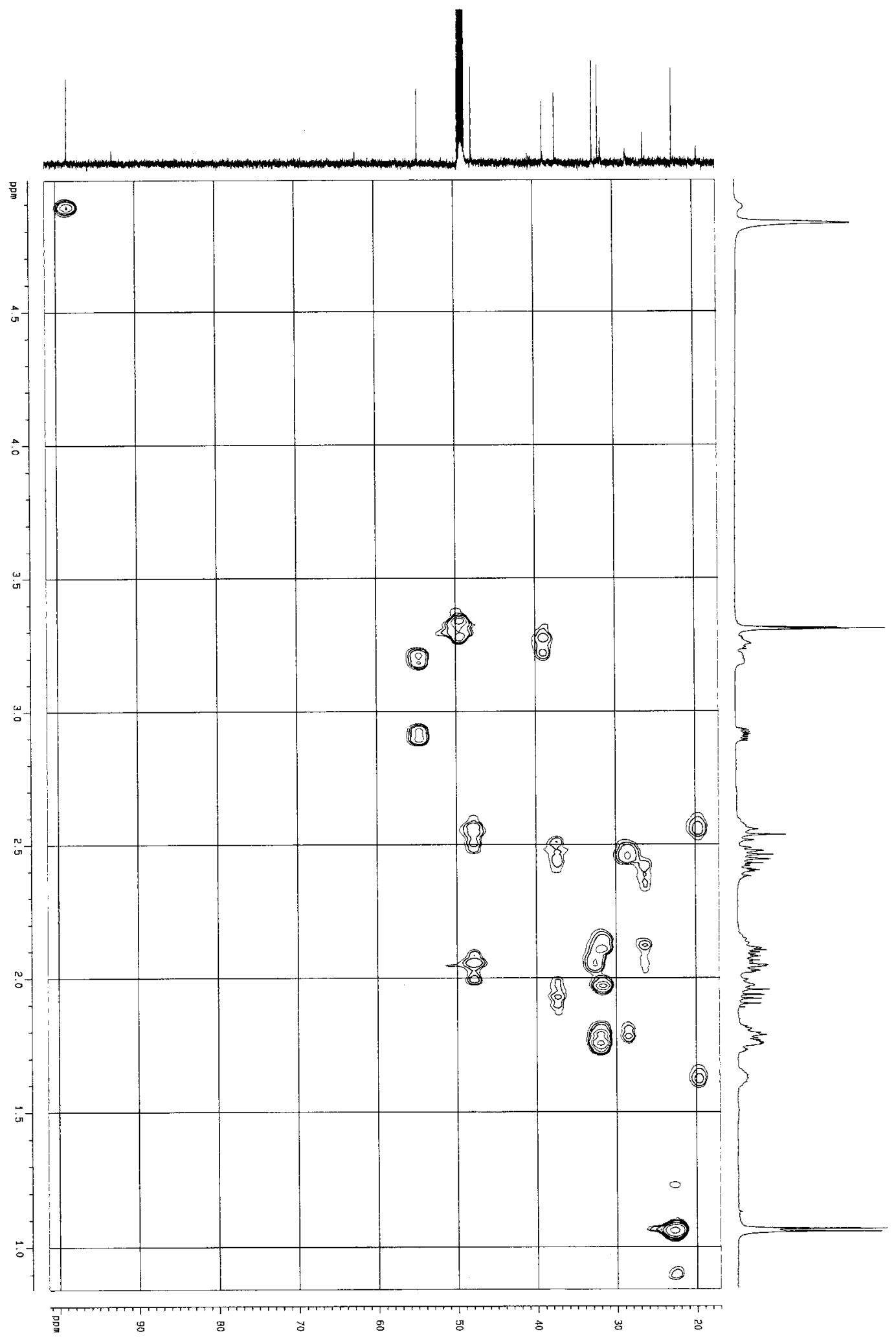

Figure S6. $\mathrm{HMQC}$ spectrum of sieboldine $\mathrm{A}(\mathbf{1})$ in $\mathrm{CD}_{3} \mathrm{OD}$. 


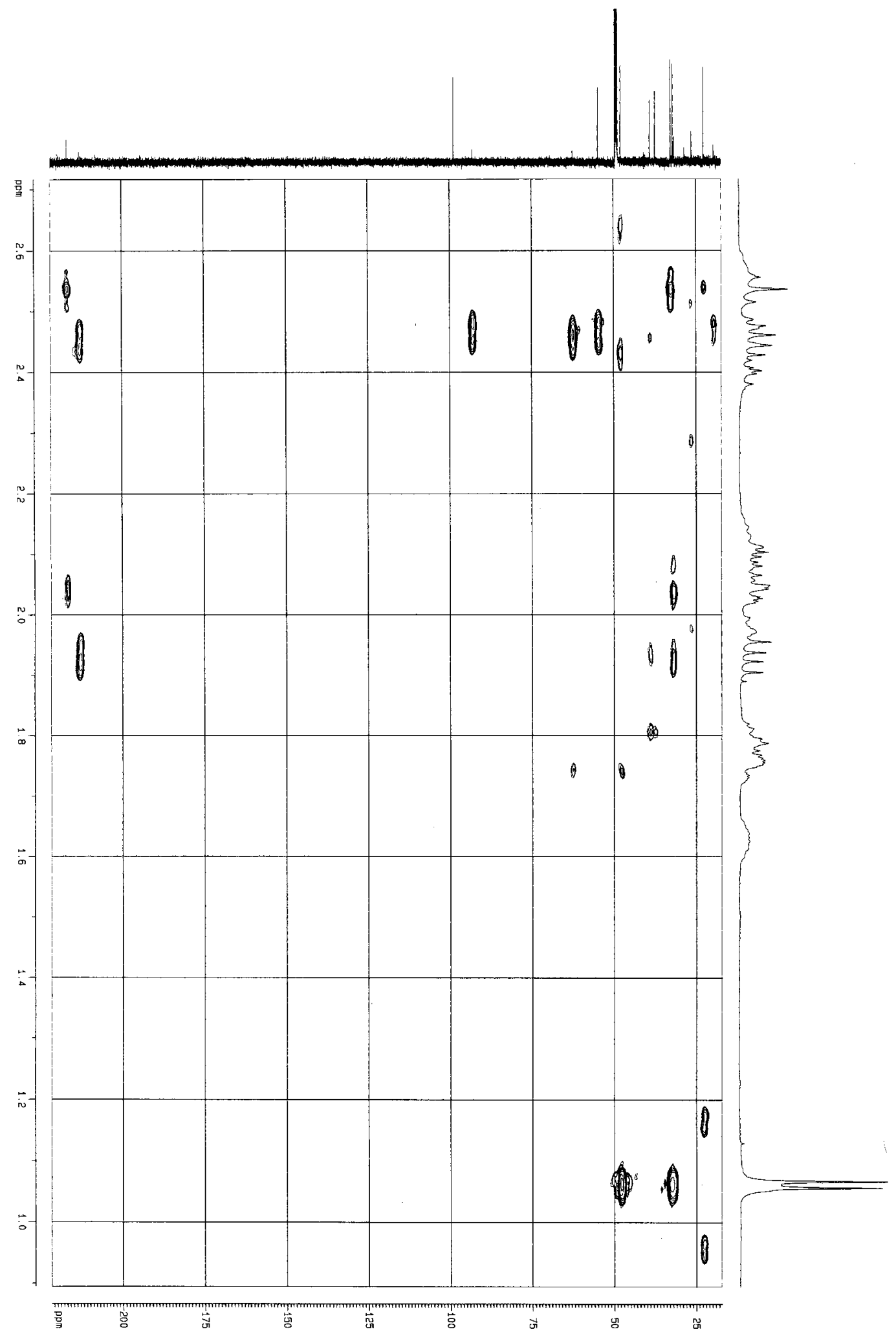

Figure S7. $\mathrm{HMBC}$ spectrum of sieboldine $\mathrm{A}(\mathbf{1})$ in $\mathrm{CD}_{3} \mathrm{OD}$. 